\title{
SIZE AND KINSHIP AFFECT SUCCESS OF CO-FOUNDING LASIUS PALLITARSIS QUEENS*
}

\author{
By Peter Nonacs \\ Museum of Comparative Zoology, Harvard University, \\ Cambridge, MA 02138, USA
}

\section{INTRODUCTION}

Ant queens often found new colonies by raising their first brood of workers alone, using only their own metabolic reserves (claustrality). Many species vary this theme by having several queens cooperate to raise a common first brood (pleometrosis). Pleometrosis can have mutualistic benefits for all members such as, increased queen survivorship, more efficient worker production, and advantages in intercolony competition amongst founding colonies (Bartz and Hölldobler 1982, Rissing and Pollock 1988). It is also, however, a situation of intense individual competition because in most species, only one or a few queens will survive from the initial group (Hölldobler and Wilson 1977). With pleometrosis having both associated costs and benefits, it might be expected that queens would exhibit preferences for joining certain groups. Several bases for choice have been experimentally tested.

Foremost among these is the effect of kinship, but evidence from a wide range of species suggests that ant queens do not preferentially join or avoid kin when given a choice of pleometrotic partners under laboratory conditions (Rissing and Pollock 1988, Nonacs 1989). Furthermore, electrophoresis of naturally occurring founding groups of Acromyrmex versicolor and Versomessor pergandei indicates that kin groups randomly associate (Hagen et al. 1988). Finally, in a theoretical treatment of nest site selection, Nonacs (1989) found that with high mortality rates during search, discriminating potential partners based on degree of relatedness only marginally increases fitness, and therefore predicted that kin discrimination should be rare in ants.

Nonacs also predicted that potential competitive interactions between members of pleometrotic groups would have a much greater effect on nest site selection than would kinship. In testing

*Manuscript received by the editor May 10, 1990. 
this, Nonacs (manuscript in prep.) found that in Lasius pallitarsis (Provancher), queens show no preference for kin, but show size preferences in their choice of pleometrotic partners. When given a choice between an empty nest site and one containing a queen, queens who have a clear size advantage are significantly more likely to join than those that do not. When given a choice between two nest sites, both containing queens, all size classes of queens preferentially join the smaller of the pair. Finally, queens' choices change after feeding in ways consistent with improved competitive ability: they join other queens more often and, when they do so, join larger queens.

This study examines the fate of pairs of $L$. pallitarsis queens. Its goals are: to compare the success of paired queens to single queens; to pair queens of known weight to test the effects of size differential; and to pair queens from different sib groups to test whether success rate is affected by kinship.

\section{Methods}

L. pallitarsis is a monogynous species common in the Pacific Northwest in forest and edge habitats. Sexuals are released in large mating flights on sunny afternoons in mid to late August. Pleometrosis occurs naturally with groups of queens often found together under rocks, wood and debris after mating flights. They can still be found sharing a common chamber several months after the mating flights (pers. obs.). Many alates often fly less than $20 \mathrm{~m}$ from their natal nest before shedding their wings, resulting in distinct aggregations of queens searching for nest sites in the same small region. These aggregations are characterized by high densities of wingless queens in an area (typically of diameter less than $10 \mathrm{~m}$ ) surrounded by low densities in identical physical habitat. It seems likely that such distinct aggregations are mostly nestmates.

Two L. pallitarsis colonies were observed releasing females on the afternoon of August 22, 1988, on the campus of Simon Fraser University in Burnaby, British Columbia. The queens were densely bunched on the ground and no other colonies were observed releasing sexuals in the immediate vicinity of these two. The probability that each aggregation contained only one sib group was, therefore, high. The two colonies were approximately $300 \mathrm{~m}$ apart. 
The queens were aspirated into collection jars after they had excised their wings and were clearly searching for nest sites. They were individually weighed and half of the queens were marked with a single spot of acetone-based, fingernail polish on the thorax. Nest sites were glass vials $(6 \mathrm{ml})$ which had a supply of water, blocked by a cotton plug at one end, to maintain constant humidity. For Sib Group 1, 29 vials had only one queen and another 29 had two queens. For Sib Group 2, 28 vials had one queen and 32 had two. Another 16 vials had one queen each from both sib groups. One queen of a pair was always marked. The size differences in pairs ranged from $0.4-9.4 \mathrm{mg}$ (or 1.2-39.0\%).

Once a week, for 26 weeks, I censused the vials, noting the production of larvae and when the first workers appeared. If one queen of a pair died, she was removed. Between censuses, the vials were kept in the dark and at room temperature. Queens received no food prior to the eclosion of the first workers. After worker eclosion the entire colony was moved to a $10 \mathrm{ml}$ test tube with the end filled with water and blocked by a cotton plug. The tube was kept in a $150 \mathrm{~mm}$ diameter petri dish with an artificial diet (Bhatkar and Whitcomb 1970) and pieces of mealworm provided ad libitum.

\section{RESULTS}

Pleometrosis affects both queen survival and worker production and within pairs of queens, effects of size and kinship are evident.

A. Queen Survival

After 26 weeks, $52.6 \%$ of single queens were still alive (Table 1). Among the pairs, there was a strong kin effect. At 26 weeks, $56.2 \%$ of all queens paired with non-kin were alive and this survival rate is not significantly different from that of single queens $(\mathrm{G}=0.06, \mathrm{df}=$ $1, \mathrm{NS})$. However, if queens were paired with others from the same flight group, the total survival rate was only $22.1 \%$, which is significantly less than for single queens $(\mathrm{G}=8.05, \mathrm{df}=1, \mathrm{p}<0.005)$, or non-kin pairs $(\mathrm{G}=6.48, \mathrm{df}=1, \mathrm{p}<0.025)$. The effects were consistent across both sib groups (Fig. 1). The mortality rates for single queens of Sib Group 1 began to diverge from that of kin pairs by Week 15 . The mortality rate of single queens from Sib Group 2 was similar to that of kin pairs for a longer period of time, diverging only after 20 weeks. However, by Week 26, it was significantly less. 
Table 1: Survival, mortality, larva production and worker production for single queens, kin pairs and non-kin pairs. For pairs, the results are per queen and per colony. Larvae could not be assigned to a particular queen; therefore, the data is given only per colony.

\begin{tabular}{|c|c|c|c|c|c|c|c|c|c|c|}
\hline & \multicolumn{2}{|c|}{ Alone } & \multicolumn{4}{|c|}{ Kin Pairs } & \multicolumn{4}{|c|}{ Non-Kin Pairs } \\
\hline & \multirow[b]{2}{*}{$\mathrm{N}$} & \multirow[b]{2}{*}{$\%$} & \multicolumn{2}{|c|}{ Queen } & \multicolumn{2}{|c|}{ Colony } & \multicolumn{2}{|c|}{ Queen } & \multicolumn{2}{|c|}{ Colony } \\
\hline & & & $\mathrm{N}$ & $\%$ & $\mathrm{~N}$ & $\%$ & $\mathrm{~N}$ & $\%$ & $\mathrm{~N}$ & $\%$ \\
\hline ALIVE (at 26 wks) & 30 & 52.6 & 27 & 22.1 & 23 & 37.7 & 18 & 56.2 & 12 & 75.0 \\
\hline DEAD (at 26 wks) & 27 & 47.4 & 95 & 77.9 & 38 & 62.3 & 14 & 43.8 & 4 & 25.0 \\
\hline WITH LARVAE & 24 & 42.4 & - & - & 35 & 57.4 & - & - & 11 & 68.8 \\
\hline WITH WORKERS & 4 & 7.0 & 8 & 6.6 & 8 & 13.1 & 0 & 0 & 0 & 0 \\
\hline
\end{tabular}

Marked queens did not die significantly earlier than unmarked queens when all single queens are compared (Tables 2 and 3, note that queens that lived through the entire experiment were recorded as living 27 weeks in the statistical analysis). Nor was marking a significant predictor of which queen in the non-kin pairs lived longer. However, marked queens did die significantly earlier within pairs of queens from the same flight group (Wilcoxon sign rank test, $\mathrm{p}=0.0172$ ). Within flight groups, this effect was present in both groups, but was significant only in Sib Group 2 (Table 2).

Within pairs of queens, size was not a significant predictor of which queen survived longer (Tables 2 and 3). Although heavier queens lived, on average, longer than lighter queens and the average weight of the queen that died first was less than that of her partner, in neither the kin or non-kin pairs was the larger queen significantly the more likely survivor. However, in the 6 of the 7 pairings with the greatest size differences, the larger queen did survive the smaller queen.

Besides looking at pair-wise comparisons, I also compared the average initial size of all survivors to that of all the queens who died. Among non-kin pairs, the initial size of queens alive at 26 weeks was significantly greater than the size of those that failed to survive (Table 3; $\mathrm{t}=2.11, \mathrm{df}=30, \mathrm{p}=0.043$ ).

When the two sib groups were paired, neither group demonstrated higher survivorship, as queen deaths were equally distributed (Table 2). 


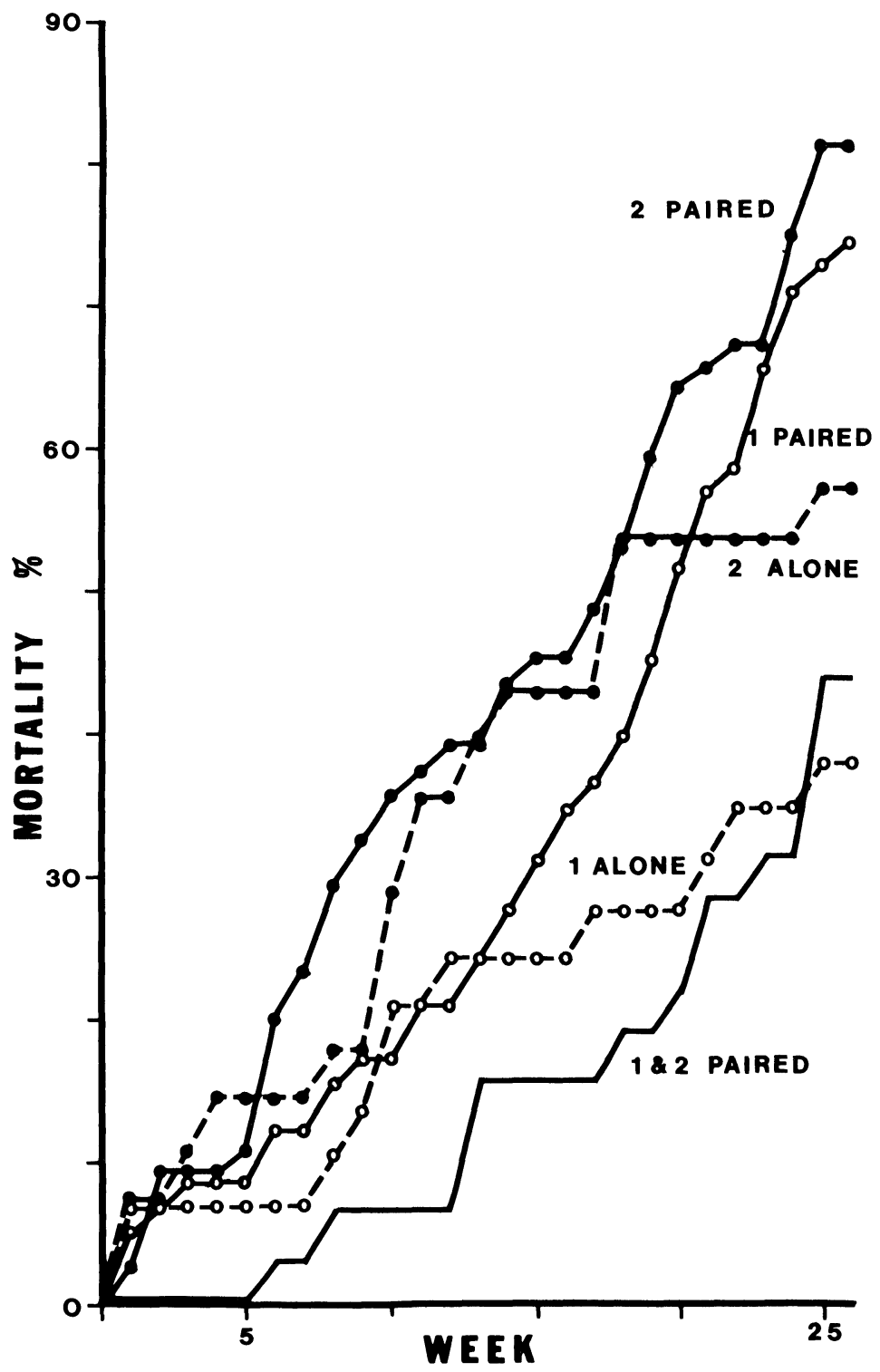

Figure 1. Cumulative percentage mortality for Kin Groups 1 and 2, when they are alone, with kin or with non-kin. Solid and dashed lines represent pairs or single queens, respectively. Treatments with only Group 1 are shown with ${ }^{\circ}$ and treatments with only Group 2 , by $\bullet$. 
Table 2: Survival of kin groups when queens were alone or with another. For single queens, this is the number of marked $(+)$ or unmarked $(-)$ queens that died over the 26 weeks. For pairs the data are presented as to which queen died first, depending on marking, weight (heavier or lighter) or kin group membership.

\begin{tabular}{|c|c|c|c|c|c|c|c|c|}
\hline \multirow[b]{3}{*}{ Kin Groups } & \multirow{2}{*}{\multicolumn{2}{|c|}{$\begin{array}{c}\text { Single } \\
\text { Mark } \\
\end{array}$}} & \multicolumn{6}{|c|}{ Pairs } \\
\hline & & & \multicolumn{2}{|c|}{ Mark } & \multicolumn{2}{|c|}{ Weight } & \multicolumn{2}{|c|}{ Group } \\
\hline & + & - & + & - & $\mathrm{H}$ & $\mathrm{L}$ & 1 & 2 \\
\hline$\# 1$ & 6 & 5 & 13 & 12 & 12 & 13 & - & - \\
\hline$\# 2$ & 9 & 7 & 19 & 8 & 14 & 13 & - & - \\
\hline$\# 1+\# 2$ & - & - & 3 & 4 & 2 & 5 & 3 & 4 \\
\hline Total & 15 & 12 & 35 & 24 & 28 & 31 & 3 & 4 \\
\hline
\end{tabular}

Cause of queen death was difficult to determine, but it seems unlikely to be due to hostile interactions between queens. Sometimes a dead queen would be found dismembered, but this could have happened before or after death. The latter seems more likely because I have never observed queens being aggressive towards each other either in this or other studies. Furthermore, many dead queens were found entirely intact and in a number of instances the censuses revealed queens alive but obviously near death. Neither these queens nor any live queen ever had noticeable wounds or body parts missing.

\section{B. Worker Production}

The proportion of colonies that produced workers was low (Table 1). Only $7 \%$ and $13 \%$ of the colonies successfully eclosed workers from single queens or kin pairs, respectively. However, not a single non-kin pair managed to mature workers for the entire 26 weeks of the experiment. It is not possible to say whether this is a significant effect because with 16 pairs to begin with, a success rate equivalent to kin pairs would predict only 2 colonies with workers.

Only $42 \%$ of the single queens produced larvae. The proportion of larvae-producing colonies was higher with paired queens, but this was expected with two potential egg-layers. If $42 \%$ of the paired queens were fertile and randomly distributed across pairs, then $66 \%$ of the pairs should have had at least one egg layer, which is close to the observed values (Table 1). The failure of non-kin pairs to mature workers, therefore, cannot be attributed to a failure or a reduced proclivity to produce larvae. 
Four single queens and eight kin pairs matured workers (Table 4). In all 8 pairs, queen number was reduced to one at some point prior to 26 weeks. In several cases, two queens survived to worker eclosion, but one died soon thereafter. It appeared that the cause of death was starvation. No hostile queen-worker interactions were observed, but inevitably one queen would become slightly physogastric and the other would wither. Workers never attacked and dismembered dying or recently dead queens, but instead would remove intact carcasses from the test tube. It was not possible to assign parentage of the workers to either queen. On average, queens with workers (defined as the survivor among pairs) were larger than those that did not (33.8 $\mathrm{mg}$ versus $33.4 \mathrm{mg}$ ). This difference was not, however, statistically significant.

The first colony to produce workers was at Week 10 and the last to do so was at Week 16. Single and paired colonies did not differ in the average time to appearance of the first workers (Table 4). Many colonies that matured no workers had larvae through to Week 26, but no pupae, so that at the termination of the experiment, none of the remaining colonies could have matured workers any time soon after. After termination of the experiment, I provided food to several queens with larvae and thereafter they successfully matured workers.

Because one queen of a pair always died, the probability that a given queen would be successful in surviving to head a colony with

Table 3: Lifespan and initial weights of queens. Values in parentheses are N's. Victor and loser refer to which queens survived or died first in the pairs. Larger and smaller refer to the initial size relationship of queens in the pairs. Values that are significantly different $(\mathrm{p}<0.05)$ are noted by $a$ (T-test) and $b$ (Wilcoxon signed-rank test).

\begin{tabular}{lclc}
\hline Initial Wt. $(\mathrm{mg})$ & Alone & With Kin & With Non-Kin \\
\hline Alive (at 26 weeks) & $33.3(30)$ & $33.1(27)$ & $34.1(18) a$ \\
Dead (at 26 weeks) & $34.1(27)$ & $33.2(95)$ & $32.9(14) a$ \\
Victor & - & $33.2(52)$ & $33.8(7)$ \\
Loser & - & $33.1(52)$ & $32.6(7)$ \\
\hline Mean Lifespan (wks) & & & \\
\hline With mark & $20.2(28)$ & $15.6(61) b$ & $22.3(16)$ \\
Without mark & $19.2(29)$ & $18.9(61) b$ & $24.1(16)$ \\
Larger queen & - & $17.4(61)$ & $23.9(16)$ \\
Smaller queen & - & $17.1(61)$ & $22.4(16)$ \\
\hline
\end{tabular}




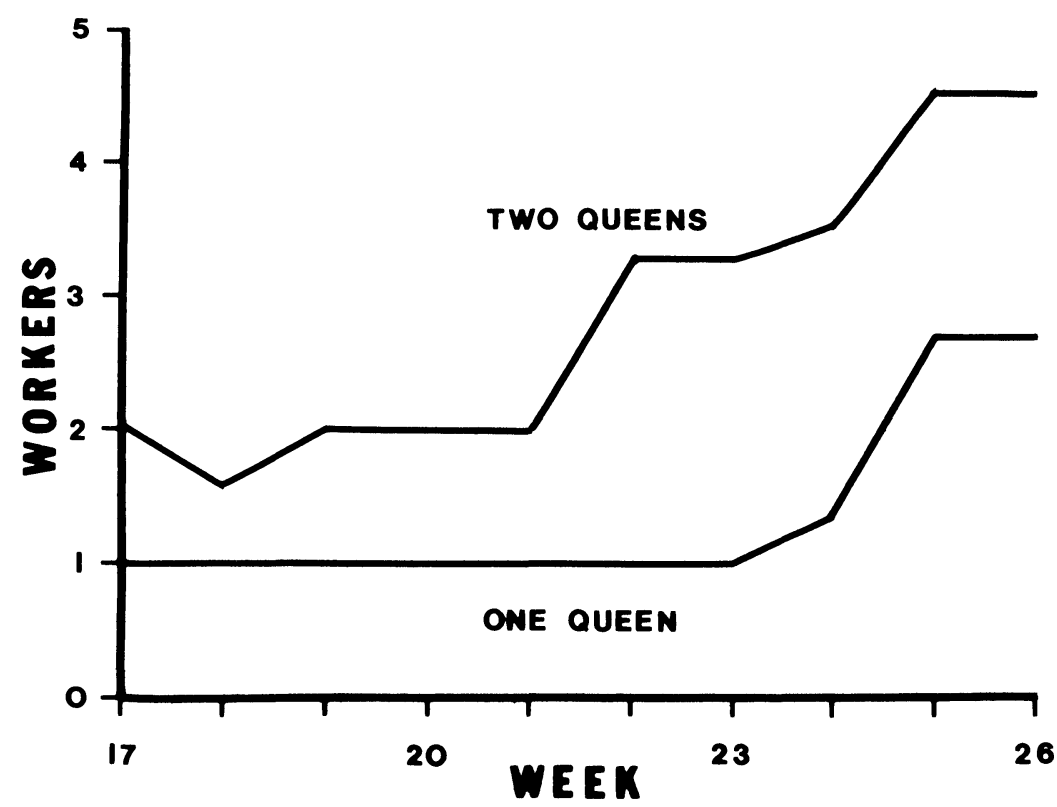

Figure 2. Average worker number in initially single-queened and two-queened colonies over the last 10 weeks of the experiment.

workers was no higher nesting with kin than nesting alone (Table 1). However, there appear to be two advantages to pleometrosis: the number of workers in the first cohort to eclose is higher (Table 4) and over the length of 26 weeks, pairs consistently have approximately twice as many workers (Fig. 2). These extra workers could be of significant advantage to colony survival. In total, across all worker-producing colonies, 34 workers eclosed in the 26 weeks. Of these, $17.6 \%$ died by the end of the experiment, as well. Considering that this is just the intrinsic mortality rate (no predation and plentiful food in the experiment), single queens in nature must be highly susceptible to becoming workerless. In this experiment, in fact, one queen who matured only one worker in the first cohort, had that worker die. She failed to mature another and was dead, herself, in two weeks.

The final push to mature workers appears to be very stressful, as suggested by queens needing to be fed to first produce workers after 16 weeks. Furthermore, the first four colonies producing workers 
were not transferred to the larger test tube or provided food. When I censused them the following week, all members of 3 of the 4 colonies were dead (these data were not included in calculating worker mortality rate above). Thereupon, I provided food immediately to colonies upon observing eclosed workers and avoided similar occurrences.

\section{DisCUSSION}

The difference in survival rates between claustral kin and non-kin Lasius pallitarsis queen pairs is the first time that a significant effect ascribable to kinship has been found during pleometrosis in ants. The significantly higher survivorship of heavier queens among nonkin pairs supports the assumption that size can be a measure of competitive advantage among ant queens and is consistent with size-based preferences exhibited by $L$. pallitarsis queens in choosing partners (Nonacs, manuscript in prep.).

Size also appears to be an advantage for pleometrotic queens in other species such as Atta texana and Myrmecocystus mimicus, where the heavier queens in groups have higher survivorship (Bartz and Hölldobler 1982, Mintzer 1987). Size, however, appears to have no advantage for Acromyrmex versicolor queens. Large queens do not force smaller queens into foraging (the dangerous task) in this non-claustral, fungus-garden ant (Rissing et al. 1989). Because groups are not kin (Hagen et al. 1988), the appparently random nature by which one queen of group becomes the foraging specialist is paradoxical. Rissing et al. suggest maximization of group fitness favors sacrificial behavior among queens over a size based competition, but the same benefits would accrue if size asymmetries were used to rapidly impose foraging roles. One possible complication in the Rissing et al. experiment was that foraging queens never experiencing any risk. Worker foraging behavior is greatly affected by encounters with potential mortality agents (Nonacs and Dill 1988) and queens' willingness to forage may be equally affected.

The main advantage of pleometrosis demonstrated by this experiment is that queens are more likely to gain control of a larger initial brood. The first brood of $L$. pallitarsis queens is 1-2 workers per queen, which is less than many species in the genus Lasius (S. Cover, pers. comm.). The first workers suffered a high mortality rate even in the absence of any predation losses. In nature, both the intrinsic 
Table 4: Data of colonies that produced workers plus standard errors.

\begin{tabular}{lrr}
\hline & \multicolumn{1}{c}{1 Queen } & \multicolumn{1}{c}{$\frac{2 \text { Queens }}{8}$} \\
\cline { 2 - 2 } \multicolumn{1}{c}{$N$} & \multicolumn{1}{c}{4} & \multicolumn{1}{c}{8} \\
\hline Avg. Week of 1st Worker & $13.00 \pm 1.47$ & $13.25 \pm 0.37$ \\
Avg. Workers in 1st Brood & $1.25 \pm 0.25$ & $1.88 \pm 0.35$ \\
Avg. Workers at 26 Weeks & $2.67 \pm 0.88$ & $4.50 \pm 0.87$ \\
\hline
\end{tabular}

mortality rate and predation are likely to combine in resulting in a high colony failure rate due to loss of all workers. The results here suggest that if all the initial workers are lost, queens are unlikely to have the metabolic reserves to replace them.

A paradox resulting from this study is that although both kinship and size had a significant effect on survival, L. pallitarsis queens' joining behavior in forming pleometrotic pairs is influenced only by size differences and not kinship (Nonacs, manuscript in prep.).

The differing results may be less problematical if one considers that the two experiments looked at different aspects of the founding process: site selection versus claustral behavior. Although identifying kinship of a potential partner may have little benefit in joining behavior (Nonacs 1989), this may not necessarily extend into treating kin and non-kin identically while claustral. $L$. pallitarsis queens may use size and condition joining rules because they are never harmful and at times could be beneficial. When kin are joined, size is neutral with large queens neither doing significantly better or worse than small queens. However, when non-kin are joined, large queens survive significantly longer. Furthermore, a simple rule for joining would suffice: join if one is large and in good condition. This would require the queen to only gauge her own self and, unlike kin discrimination, the queen would not need to specifically characterize potential partners.

In conclusion, this study is the first to show significant kin effects in the claustral colony-founding stage of any ant species and that size of queens also plays a role in the non-kin interactions. Although kin effects in ants may not influence the initial formation of colonies, these results should caution against a blanket assumption that kinship is irrelevant throughout the entire process that leads to successful worker maturation. It is clear that at least in L. pallitarsis, neither formation of pleometrotic groups nor success within those groups is entirely based on random processes. 


\section{SUMMARY}

Colony founding by pairs of kin and non-kin queens in the ant Lasius pallitarsis was examined and compared to the success rate of single queens. The main advantage of pleometrosis in this species was that one queen of a pair would eventually gain control of a larger colony than those produced by single queens. When kin were paired, queen mortality was significantly higher than that of single queens or non-kin pairs. Non-kin pairs, although having a higher survival rate, did not produce any workers during the length of the experiment, while single queens and kin pairs did mature workers. Size of the queens was a significant factor among non-kin pairs: larger queens had higher survivorship. The results are discussed in relation to nest site preferences demonstrated by $L$. pallitarsis in other experiments.

\section{ACKNOWLEDGMENTS}

I thank N. Carlin and S. Cover for their helpful comments on this project and a previous manuscript. I thank Simon Fraser University for maintaining a habitat so suitable for Lasius pallitarsis' sexual production!

\section{REFERENCES}

BARTZ, S. H. AND Hölldobler, B.

1982. Colony founding in Myrmecocystus mimicus Wheeler (Hymenoptera: Formicidae) and the evolution of foundress associations. Behav. Ecol. Sociobiol. 10: 137-147.

BhATKAR, A. AND Whitcomb, W. H.

1970. Artificial diet for rearing various species of ants. Flor. Entomol. 53: 229-231.

Hagen, R. H., Smith, D. R. And Rissing, S. W.

1988. Genetic relatedness among co-foundresses of two desert ants, Veromessor pergandei and Acromyrmex versicolor (Hymenoptera: Formicidae). Psyche 95: 191-202.

HölLDOBLER, B. AND WILSON, E. O.

1977. The number of queens: an important trait in ant evolution. Naturwissenschaften 64: 8-15.

Mintzer, A. C.

1987. Primary polygyny in the ant Atta texana: number and weight of females and colony foundation success in the laboratory. Insectes Soc. 34: 108-117. 
Nonacs, $\mathrm{P}$.

1989. Competition and kin discrimination in colony founding by social Hymenoptera. Evol. Ecol. 3: 221-235.

Nonacs, P. AND Dill, L. M.

1988. Foraging response of the ant Lasius pallitarsis to food sources with associated mortality risk. Insectes Soc. 35: 293-303.

Rissing, S. W. AND Pollock, G. B.

1988. Pleometrosis and polygyny in ants. In Jeanne, R. L. (ed.), Interindividual Behavioral Variability in Social Insects, Westview Press, Boulder, pp. 179-222.

Rissing, S. W., Pollock, G. B., Higgins, M. R., Hagen, R. H. and Smith, D. R.

1989. Foraging specialization without relatedness or dominance among cofounding ant queens. Nature 338: $420-442$. 

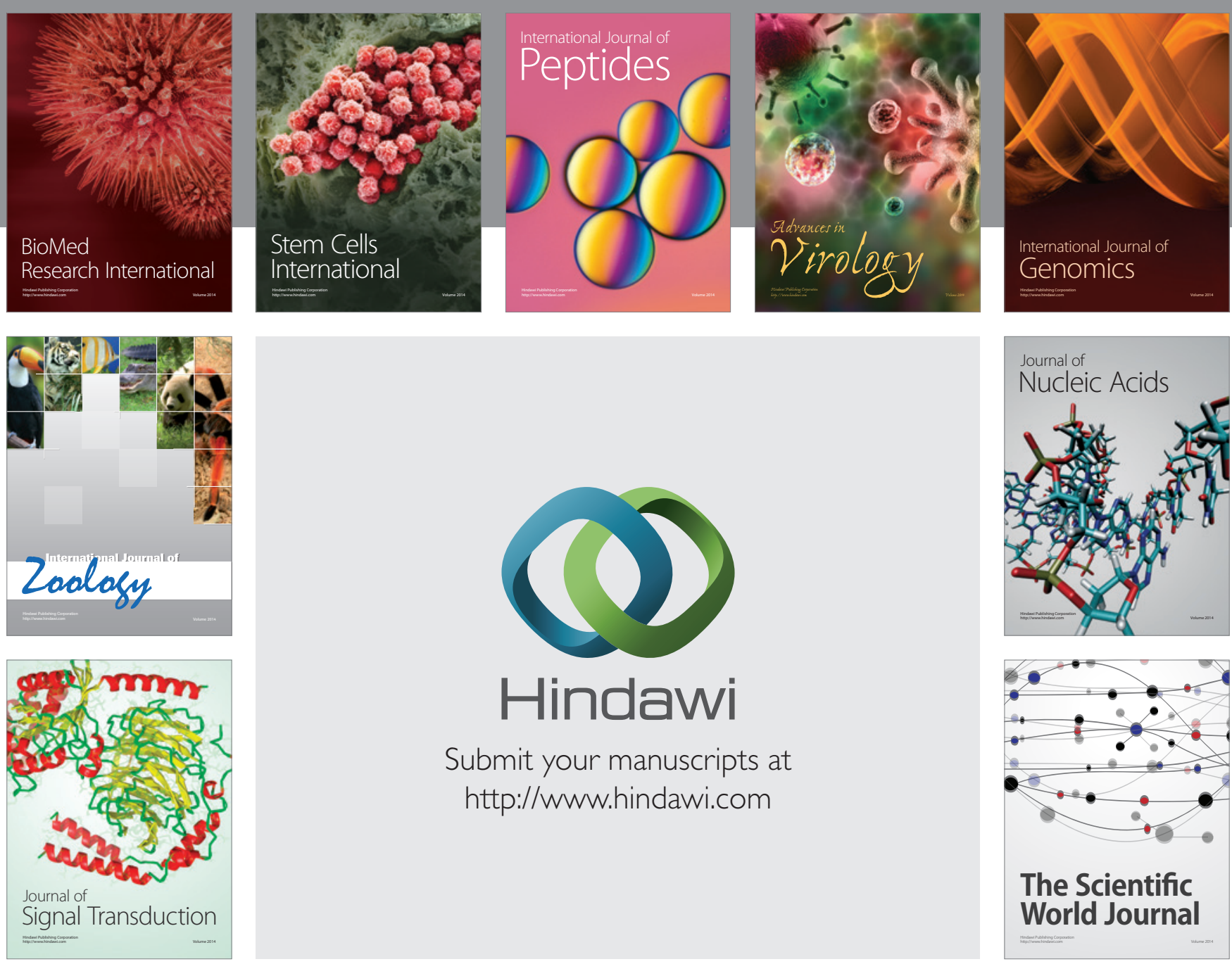

Submit your manuscripts at

http://www.hindawi.com
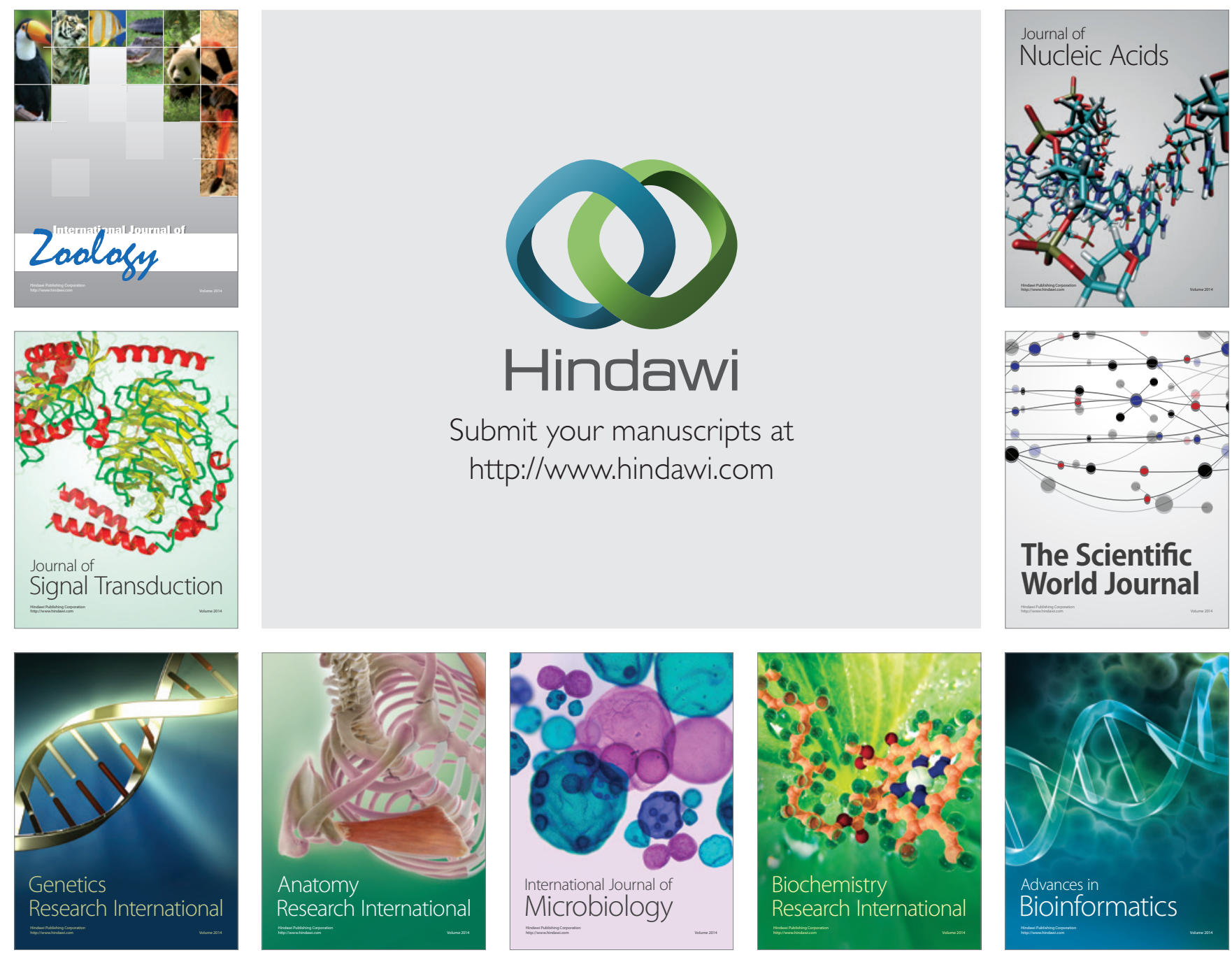

The Scientific World Journal
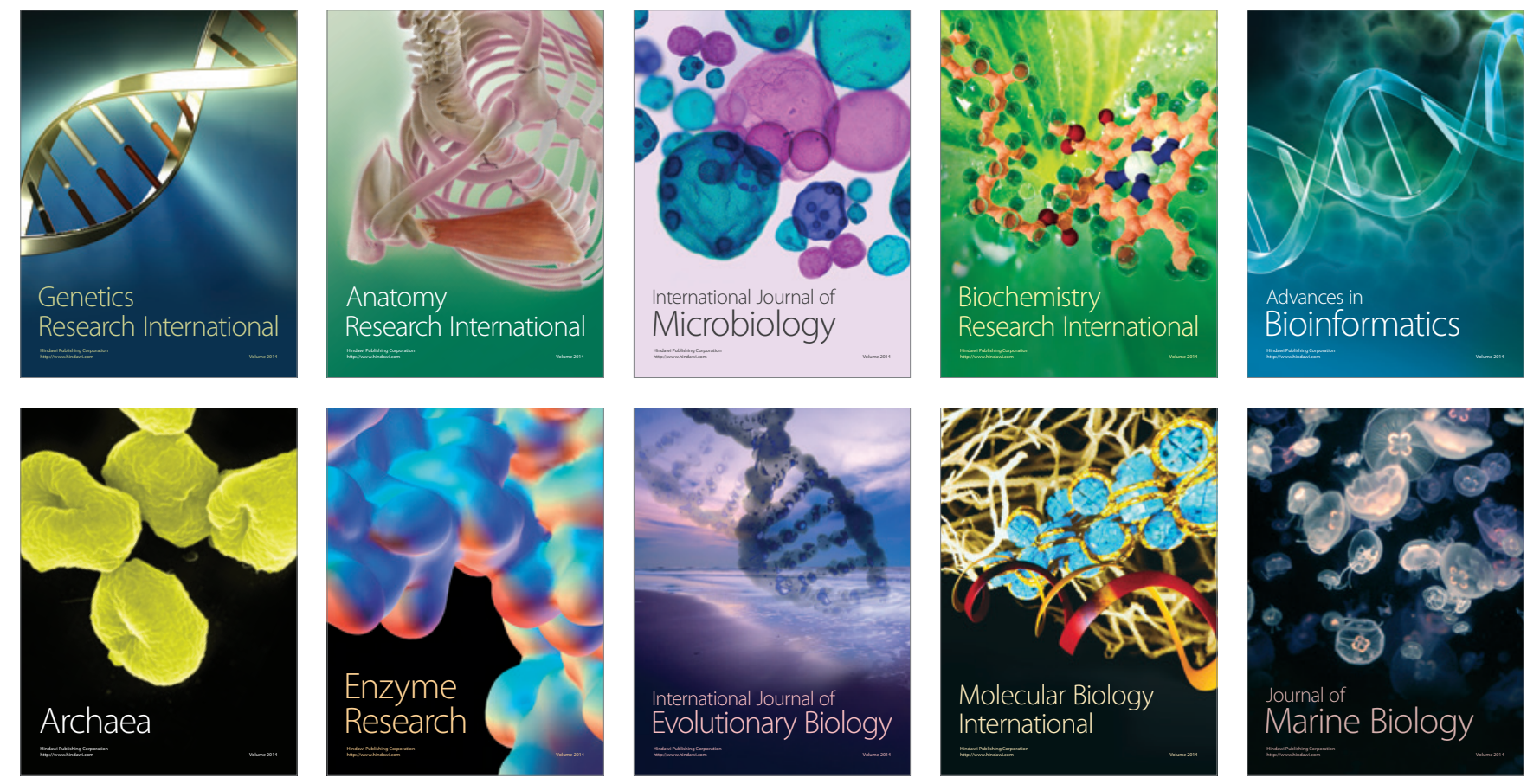